\title{
Early Transient Visual Acuity Loss After LASIK Due to Steroid-induced Elevation of Intraocular Pressure
}

\author{
Joseph Frucht-Pery, MD; David Landau, MD; Frederik Raiskup, MD; Faik Orucov, MD; \\ Eyal Strassman, MD; Eytan Z. Blumenthal, MD; Abraham Solomon, MD
}

\section{ABSTRACT}

PURPOSE: To report the clinical course of early transient reduction of uncorrected visual acuity (UCVA) after LASIK surgery resulting from steroid-induced elevation of intraocular pressure (IOP).

METHODS: Twenty-nine eyes of 15 patients who received topical corticosteroids after uneventful myopic LASIK surgery and had a decrease in UCVA within the first 3 weeks were evaluated retrospectively.

RESULTS: Intraocular pressure increased by 4 to 30 $\mathrm{mmHg}$ from preoperative to postoperative days 4 to 20 . Twenty-seven of 29 eyes had a decrease in uncorrected visual acuity and/or BSCVA. All flaps, except one, had edema without evidence of inflammation in the interface or the remainder of the cornea. Discontinuation of topical corticosteroids and application of anti-glaucoma medications resulted in a decrease of IOP to normal levels and recovery of BSCVA.

CONCLUSIONS: Early onset steroid-induced elevation of IOP may cause a sudden decrease in UCVA after LASIK. Rapid diagnosis and treatment can control $\mathrm{IOP}$ and recover the visual loss. Patients and surgeons should be aware of early loss of vision as a result of steroid-induced IOP elevation after LASIK surgery. [J Refract Surg. 2006;xx:xxx-xxx.]

Journal of Refractive Surgery Volume XX Month/Month 200X aser in situ keratomileusis (LASIK) is a common surgical procedure performed all over the world. Millions of people have undergone this surgery. Many complications of LASIK have been described in the ophthalmic literature. Elevation of intraocular pressure (IOP) after LASIK has been described as a dramatic event with decrease in uncorrected visual acuity (UCVA), corneal edema and inflammation, accumulation of fluid in the interface between the flap and the cornea, and erroneously low measurements of IOP with applanation tonometry. ${ }^{1-4}$ However, these dramatic events are rare.

Most refractive surgeons routinely use topical corticosteroids after LASIK surgery. The dose and duration of steroid application differ according to the decision of each surgeon. The use of steroids may cause steroid-induced IOP elevation. The intraocular hypertensive effect of topical steroids is well known in ophthalmology. Becker ${ }^{5}$ and Armaly ${ }^{6}$ found that $30 \%$ to $40 \%$ of the normal population may be intermediate responders with a pressure increase of at least $6 \mathrm{mmHg}$, and a small group of high responders may have elevations of 16 mmHg. Armaly ${ }^{6}$ reported a hypertensive effect at the end of the first week in normal patients, with a mean increase in pressure of $19 \%$. High responders had a more rapid and higher increase in pressure (increase of $60 \%$ ) at the end of the first week of steroid therapy. ${ }^{6,7}$

Mild increase of IOP after LASIK will not affect the vision of most patients and will remain unidentified after the discontinuation of corticosteroids. A significant increase in IOP during the first postoperative days, without interlamellar inflammation, may cause flap edema, changes in corneal con-

From the Department of Ophthalmology, Hadassah - Hebrew University Mrom the Department of Center, Jerusalem, Israel.

The authors have no financial or proprietary interest in the materials presented herein.

Correspondence: Abraham Solomon, MD, Dept of Ophthalmology, Hadassah University Hospital, POB 12000, Jerusalem, Israel. Tel: 9722 6777111; Fax: 9722 6428896; E-mail: avisol@md.huji.ac.il

Received: August 6, 2005

Accepted: June 7, 2006 
tour, and visual symptoms.

In this study, we present a group of patients who had an early transient decrease of UCVA and best spectaclecorrected visual acuity (BSCVA) after LASIK, which was associated with steroid-induced elevation of the IOP. Unlike previous reports describing interface fluid or interface keratitis associated with IOP elevation after LASIK,, ${ }^{4,8}$ our patients presented with flap edema but without signs of interface fluid or inflammatory response.

\section{PATIENTS AND METHODS}

We reviewed the files of 1492 patients who underwent LASIK by one surgeon (J.F.P.) between November 2002 and December 2003 at the Laser Vision Correction Center, Department of Ophthalmology, Hadassah University Hospital, Jerusalem, Israel. Fifteen consecutive healthy patients ( 11 men and 4 women) aged 22 to 56 years who had postoperative intraocular pressures (IOP) elevations ( $\geqslant 4 \mathrm{mmHg}$, as compared to preoperative values) were identified. None of the 15 patients reported a family history of systemic or ophthalmic diseases.

Prior to surgery each eye underwent a complete eye examination. Uncorrected visual acuity (UCVA) and best spectacle-corrected visual acuity (BSCVA), IOP measurement with applanation tonometry, slit-lamp evaluation of the anterior segment, and direct/indirect funduscopy were evaluated. Schirmer test, pupil size evaluation, and topography with EyeSys (EyeSys Technologies, Houston, Tex) and Orbscan (Bausch \& Lomb, Rochester, NY) systems were routinely done in all eyes. A standard Snellen chart was used to measure UCVA and BSCVA.

All eyes underwent LASIK using the Technolas $217 \mathrm{Z}$ laser (Bausch \& Lomb). In 8 eyes (4 patients), a wavefront-guided ablation was performed (Zyoptix System, Bausch \& Lomb). In the remaining 21 eyes (11 patients), a standard plano-scan ablation was applied. Flaps of 8.5 to $9.5 \mathrm{~mm}$ were cut using the Hansatome microkeratome (Bausch \& Lomb), and the corrected optical zones ranged from 5.5 to $7.0 \mathrm{~mm}$ in diameter. All eyes except one had uneventful procedures. In one eye, an epithelial erosion $(2.0 \times 1.5 \mathrm{~mm})$ occurred, which healed within the first two postoperative days with the help of a bandage contact lens.

Routine postoperative treatment included topical application of $0.5 \%$ prednisolone acetate 6 times a day for the first 4 postoperative days, tapered to 3 times a day for the following 10 days. Topical $0.3 \%$ lomefloxacine (Novartis Ophthalmics, Hettlingen, Switzerland) was used 4 times a day for the first 4 days. When patients complained of decreased vision postoperatively, and the postoperative UCVA was lower than the preoperative BSCVA by $\geqslant 2$ lines, a complete ocular evaluation was performed, including applanation to- nometry and refraction. The IOP was measured with Goldmann tonometry in the center of the flap.

When the postoperative IOP was $>20 \mathrm{mmHg}$, topical corticosteroids were discontinued and topical $0.5 \%$ timolol maleate twice daily was started. If the IOP was $>30 \mathrm{mmHg}$, topical $2 \%$ pilocarpine 4 times daily was added as well. The topical pilocarpine was discontinued in all patients after 48 hours, when a decrease in IOP was noted. The topical timolol was maintained until the next follow-up, usually within 1 or 2 weeks, when the IOP returned to preoperative levels.

\section{RESULTS}

Preoperatively, all patients presented with myopia from -1.00 to -13.25 diopters (D) (mean: $-5.4 \pm 2.7$ D) and astigmatism from 0 to $5.00 \mathrm{D}$ (Table). Best spectacle-corrected visual acuity was $\geqslant 20 / 20$ in 21 eyes and $20 / 25$ to 20/40 in 8 eyes. Intraocular pressure was between 11 and $16 \mathrm{mmHg}$. The remainder of the eye examinations, including evaluation of the anterior and posterior segments, corneal topography, and Schirmer's test, were unremarkable.

One day after LASIK all eyes had UCVA within 2 lines of the preoperative BSCVA, except for one patient who was corrected for monovision. Thirteen of the 15 patients were concerned due to a decrease in UCVA and blurred vision, and called at least once before the scheduled eye examination. These patients attended an unscheduled eye examination within 4 to 20 days postoperatively, and only 2 patients came for a scheduled appointment (Table).

Postoperatively, most eyes presented with edema of the LASIK flap without epithelial edema, whereas the conjunctiva was quiet or mildly hyperemic (Fig 1). No signs of interface inflammation were noted, and there was no interface fluid in any of the patients. In all patients, the corneal stroma was clear with no signs of edema. In all 29 eyes, the applanation tonometry measurements of the IOP were between 16 and $42 \mathrm{mmHg}$ and were higher than the preoperative IOP measurement by 4 to $30 \mathrm{mmHg}(P=.001)$. Best spectacle-corrected visual acuity decreased in 23 eyes by 1 to 3 lines (by 1 line in 11 eyes, by 2 lines in 8 eyes, and by 3 lines in 4 eyes) and remained unchanged in 6 eyes. Twenty-five of 29 eyes had myopia with spherical equivalent refraction ranging from -0.50 to $-3.50 \mathrm{D}$. The mean spherical equivalent refraction in all 29 eyes was $-1.18 \mathrm{D}$.

After the IOP dropped to preoperative (or lower) levels, the IOP-induced myopic shift decreased in 27 eyes by $-0.25 \mathrm{D}$ to $-2.37 \mathrm{D}$ (mean: $-0.89 \mathrm{D})$. In 2 eyes, the spherical equivalent refraction did not change despite the decrease in the IOP. 
TABLE

Changes in Spherical Equivalent Refraction, Visual Acuity, and Intraocular Pressure Following Steroid-induced Elevated Intraocular Pressure After LASIK

\begin{tabular}{|c|c|c|c|c|c|c|c|c|}
\hline \multirow[b]{2}{*}{ No./Sex/Age (y) } & \multirow[b]{2}{*}{ Exam Day } & \multicolumn{2}{|c|}{ Preoperatively } & \multicolumn{3}{|c|}{ Postoperatively } & \multicolumn{2}{|c|}{ Final Examination } \\
\hline & & SEQ/IOP & BSCVA & IOP & UCVA/BSCVA & SEQ & SEQ/IOP & UCVA/BSCVA \\
\hline 1/M/46 & 20 nsch & $\begin{array}{l}-2.67 / 13 \\
-1.42 / 13\end{array}$ & $\begin{array}{l}1.2 \\
1.2\end{array}$ & $\begin{array}{l}36 \\
30\end{array}$ & $\begin{array}{l}0.4 / 0.8 \\
0.3 / 0.7\end{array}$ & $\begin{array}{l}-1.75 \\
-1.12\end{array}$ & $\begin{array}{l}0.00 / 10 \\
0.00 / 10\end{array}$ & $\begin{array}{l}1.2 / 1.2 \\
1.2 / 1.2\end{array}$ \\
\hline $2 / \mathrm{M} / 26$ & 9 nsch & $\begin{array}{l}-7.50 \\
-7.75\end{array}$ & $\begin{array}{l}0.8 \\
0.8\end{array}$ & $\begin{array}{l}28 \\
31\end{array}$ & $\begin{array}{l}0.5 / 0.7 \\
0.2 / 0.7\end{array}$ & $\begin{array}{l}-1.50 \\
-3.50\end{array}$ & $\begin{array}{l}-0.37 / 14 \\
-1.50 / 15\end{array}$ & $\begin{array}{l}0.7 / 0.8 \\
0.7 / 0.8\end{array}$ \\
\hline $3 / \mathrm{M} / 43$ & $5 \mathrm{nsch}$ & $\begin{array}{c}-4.5 / 12 \\
-3.92 / 12\end{array}$ & $\begin{array}{l}0.8 \\
1.2\end{array}$ & $\begin{array}{l}34 \\
32\end{array}$ & $\begin{array}{l}0.1 / 0.7 \\
0.5 / 0.8\end{array}$ & $\begin{array}{l}-2.25 \\
-0.75\end{array}$ & $\begin{array}{l}-1.50 / 13 \\
+0.50 / 10\end{array}$ & $\begin{array}{c}0.25 / 0.8 \\
1.0 / 1.2\end{array}$ \\
\hline 4/F/34 & $14 \mathrm{sch}$ & $\begin{array}{l}-4.75 / 15 \\
-4.50 / 14\end{array}$ & $\begin{array}{l}0.6 \\
0.8\end{array}$ & $\begin{array}{l}30 \\
28\end{array}$ & $\begin{array}{l}0.5 / 0.6- \\
0.6 / 0.8-\end{array}$ & $\begin{array}{l}-0.75 \\
-0.87\end{array}$ & $\begin{array}{l}-0.5 / 13 \\
-0.3 / 11\end{array}$ & $\begin{array}{l}0.6 / 0.8 \\
0.8 / 1.0\end{array}$ \\
\hline 5/M/36 & $14 \mathrm{sch}$ & $\begin{array}{l}-2.50 / 13 \\
-2.75 / 13\end{array}$ & $\begin{array}{l}1.2 \\
1.2\end{array}$ & $\begin{array}{l}40 \\
42\end{array}$ & $\begin{array}{l}0.4 / 0.8 \\
0.3 / 0.6\end{array}$ & $\begin{array}{l}-1.25 \\
-1.25\end{array}$ & $\begin{array}{c}0.2 / 13 \\
-0.12 / 12\end{array}$ & $\begin{array}{l}1.0 / 1.2 \\
1.0 / 1.0\end{array}$ \\
\hline $6 / M / 25$ & 19 nsch & $\begin{array}{l}-4.17 / 15 \\
-4.25 / 15\end{array}$ & $\begin{array}{l}1.2 \\
1.2\end{array}$ & $\begin{array}{l}30 \\
28\end{array}$ & $\begin{array}{l}0.8 / 1.0 \\
1.0 / 1.0\end{array}$ & $\begin{array}{l}-0.25 \\
-0.25\end{array}$ & $\begin{array}{l}0.25 / 12 \\
0.25 / 13\end{array}$ & $\begin{array}{l}1.0 / 1.2 \\
1.2 / 1.2\end{array}$ \\
\hline $7 / M / 44$ & 12 nsch & $\begin{array}{l}-6.12 / 14 \\
-7.70 / 12\end{array}$ & $\begin{array}{l}1.0 \\
1.0\end{array}$ & $\begin{array}{l}31 \\
36\end{array}$ & $\begin{array}{l}0.5 / 1.0 \\
0.3 / 0.8\end{array}$ & $\begin{array}{l}-1.25 \\
-2.37\end{array}$ & $\begin{array}{c}-0.50 / 11 \\
0.00 / 10\end{array}$ & $\begin{array}{c}0.9 / 1.0+ \\
1.2 / 1.2\end{array}$ \\
\hline $8 / M / 21$ & 16 nsch & $\begin{array}{l}-6.83 / 12 \\
-8.34 / 13\end{array}$ & $\begin{array}{l}1.0 \\
1.0\end{array}$ & $\begin{array}{l}16 \\
22\end{array}$ & $\begin{array}{l}0.8 / 1.0 \\
0.6 / 0.7\end{array}$ & $\begin{array}{c}0.00 \\
-0.25\end{array}$ & $\begin{array}{l}0.00 / 12 \\
0.50 / 13\end{array}$ & $\begin{array}{l}1.0 / 1.2 \\
0.7 / 0.8\end{array}$ \\
\hline 9/M/56 & 6 nsch & $\begin{array}{l}-2.00 / 15 \\
-4.75 / 15\end{array}$ & $\begin{array}{l}1.0 \\
0.9\end{array}$ & $\begin{array}{l}19 \\
28\end{array}$ & $\begin{array}{l}0.5 / 0.8 \\
0.3 / 0.5\end{array}$ & $\begin{array}{l}-0.50 \\
-1.25\end{array}$ & $\begin{array}{l}-0.50 / 14 \\
-0.75 / 14\end{array}$ & $\begin{array}{l}0.7 / 1.0 \\
0.7 / 0.9\end{array}$ \\
\hline 10/M/36 & 4 nsch & $\begin{array}{l}-6.50 / 16 \\
-5.25 / 16\end{array}$ & $\begin{array}{l}1.0 \\
1.0\end{array}$ & $\begin{array}{l}28 \\
26\end{array}$ & $\begin{array}{l}0.3 / 0.5 \\
0.3 / 0.5\end{array}$ & $\begin{array}{l}-1.50 \\
-2.00\end{array}$ & $\begin{array}{l}-0.75 / 16 \\
-0.50 / 14\end{array}$ & $\begin{array}{l}0.7 / 1.0 \\
0.7 / 1.0\end{array}$ \\
\hline $11 / F / 25$ & 7 nsch & $\begin{array}{l}-6.75 / 12 \\
-6.87 / 12\end{array}$ & $\begin{array}{l}1.0 \\
1.0\end{array}$ & $\begin{array}{l}20 \\
17\end{array}$ & $\begin{array}{l}0.5 / 0.6 \\
0.7 / 1.0\end{array}$ & $\begin{array}{l}-0.67 \\
-0.50\end{array}$ & $\begin{array}{l}-0.25 / 13 \\
-0.25 / 13\end{array}$ & $\begin{array}{l}0.7 / 1.0 \\
0.5 / 1.0\end{array}$ \\
\hline 12/M/31 & 14 nsch & $\begin{array}{l}-4.87 / 12 \\
-5.87 / 13\end{array}$ & $\begin{array}{l}1.2 \\
1.2\end{array}$ & $\begin{array}{l}24 \\
20\end{array}$ & $\begin{array}{l}0.5 / 1.0 \\
0.7 / 1.0\end{array}$ & $\begin{array}{l}-1.25 \\
-0.75\end{array}$ & $\begin{array}{l}-0.00 / 12 \\
-0.00 / 10\end{array}$ & $\begin{array}{l}1.2 / 1.2 \\
1.2 / 1.2\end{array}$ \\
\hline $13 / \mathrm{M} / 44$ & 12 nsch & $\begin{array}{l}-13.25 / 15 \\
-11.50 / 15\end{array}$ & $\begin{array}{l}1.0 \\
0.5\end{array}$ & $\begin{array}{l}27 \\
34\end{array}$ & $\begin{array}{l}0.4 / 0.7 \\
0.1 / 0.4\end{array}$ & $\begin{array}{l}-1.75 \\
-2.25\end{array}$ & $\begin{array}{c}-0.50 / 10 \\
-0.50 / 7\end{array}$ & $\begin{array}{l}0.7 / 0.9 \\
0.4 / 0.5\end{array}$ \\
\hline $14 / F / 34$ & 11 nsch & $\begin{array}{l}-2.25 / 13 \\
-2.75 / 11\end{array}$ & $\begin{array}{l}1.0 \\
1.0\end{array}$ & $\begin{array}{l}18 \\
15\end{array}$ & $\begin{array}{l}0.5 / 0.8 \\
1.0 / 1.0\end{array}$ & $\begin{array}{l}-1.00 \\
-0.25\end{array}$ & $\begin{array}{l}-0.25 / 13 \\
-0.00 / 13\end{array}$ & $\begin{array}{l}0.8 / 1.0 \\
1.0 / 1.0\end{array}$ \\
\hline $15 / M / 50$ & 7 nsch & $-4.87 / 18$ & 0.8 & 34 & $0.3 / 0.6$ & -1.75 & $-0.50 / 11$ & $0.6 / 0.8$ \\
\hline
\end{tabular}

SEQ = spherical equivalent refraction, IOP = intraocular pressure, BSCVA = best spectacle-corrected visual acuity, UCVA = uncorrected visual acuity, sch $=$ scheduled, nsch $=$ non - scheduled

In four eyes of two patients that underwent Orbscan topography postoperatively, a remarkable posterior float was documented (Figs 2 and 3). In one of these patients, the postoperative posterior float reading was $0.154 \mathrm{~mm}$ and this decreased to 0.042 after reduction of the IOP. This reduction of the posterior float value was associated with a decrease of the IOP to the preoperative level, resolution of the flap edema, and improvement in UCVA. The Orbscan central corneal thickness reading was $343 \mu \mathrm{m}$ postoperatively, and this increased to $561 \mu \mathrm{m}$ after IOP reduction. No significant changes were noted in the anterior elevation and keratometric maps (Figs 2C, 2D, 3C, and 3D).

After discontinuation of topical steroids and use of anti-glaucoma treatment, all patients reported improved UCVA within the first week. The IOP and BSCVA returned to the preoperative values within 1 to 7 days. Flap edema and corneal haze disappeared after the IOP dropped to normal levels and the posterior float, in two patients, decreased as well. In two patients, who were examined 1 and 2 hours after the administration of the anti-glaucoma drugs, the pressures dropped by 7 to $14 \mathrm{mmHg}$, and a significant decrease of flap edema was noted. 


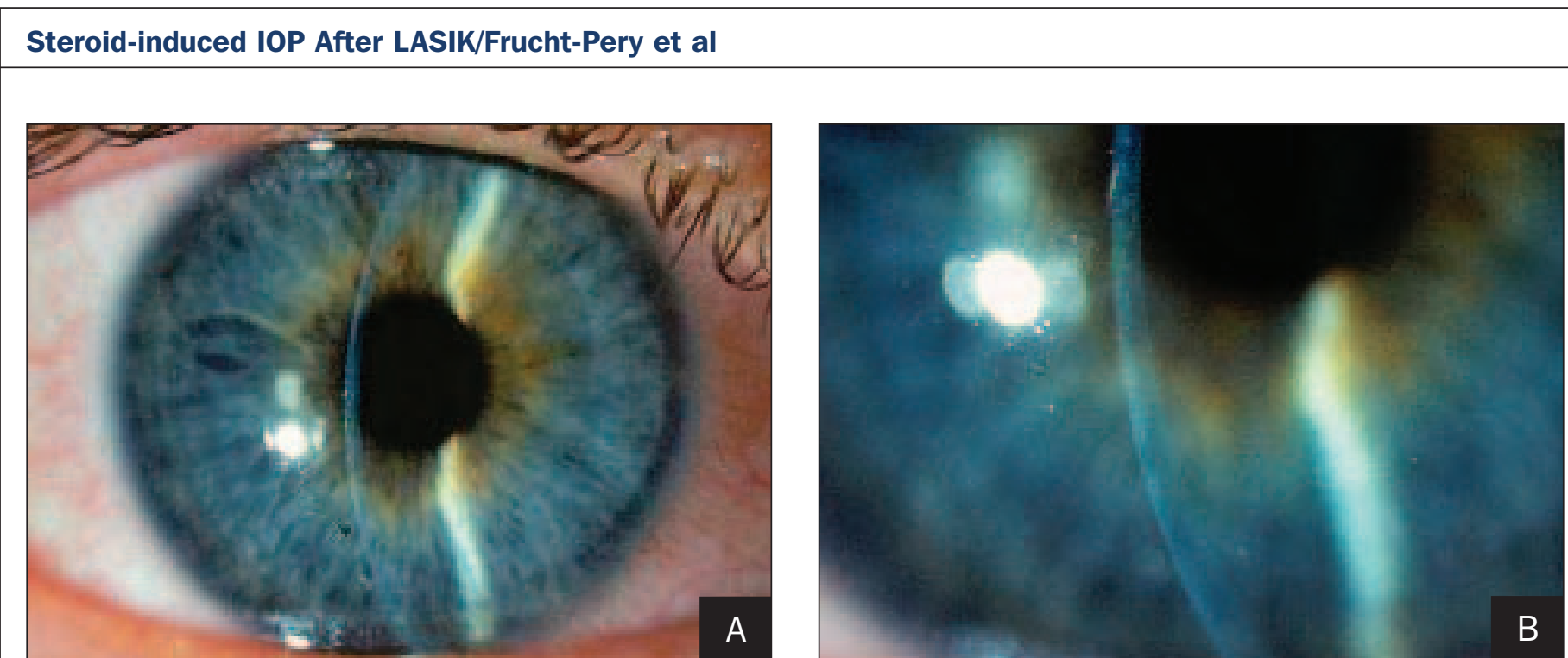

Figure 1. A) A clear cornea and mild conjunctival hyperemia in a patient presenting with elevated IOP after LASIK. B) High magnification ( $\times 16)$ slitlamp microscopy reveals edema of the LASIK flap with no epithelial edema or signs of interface inflammation.
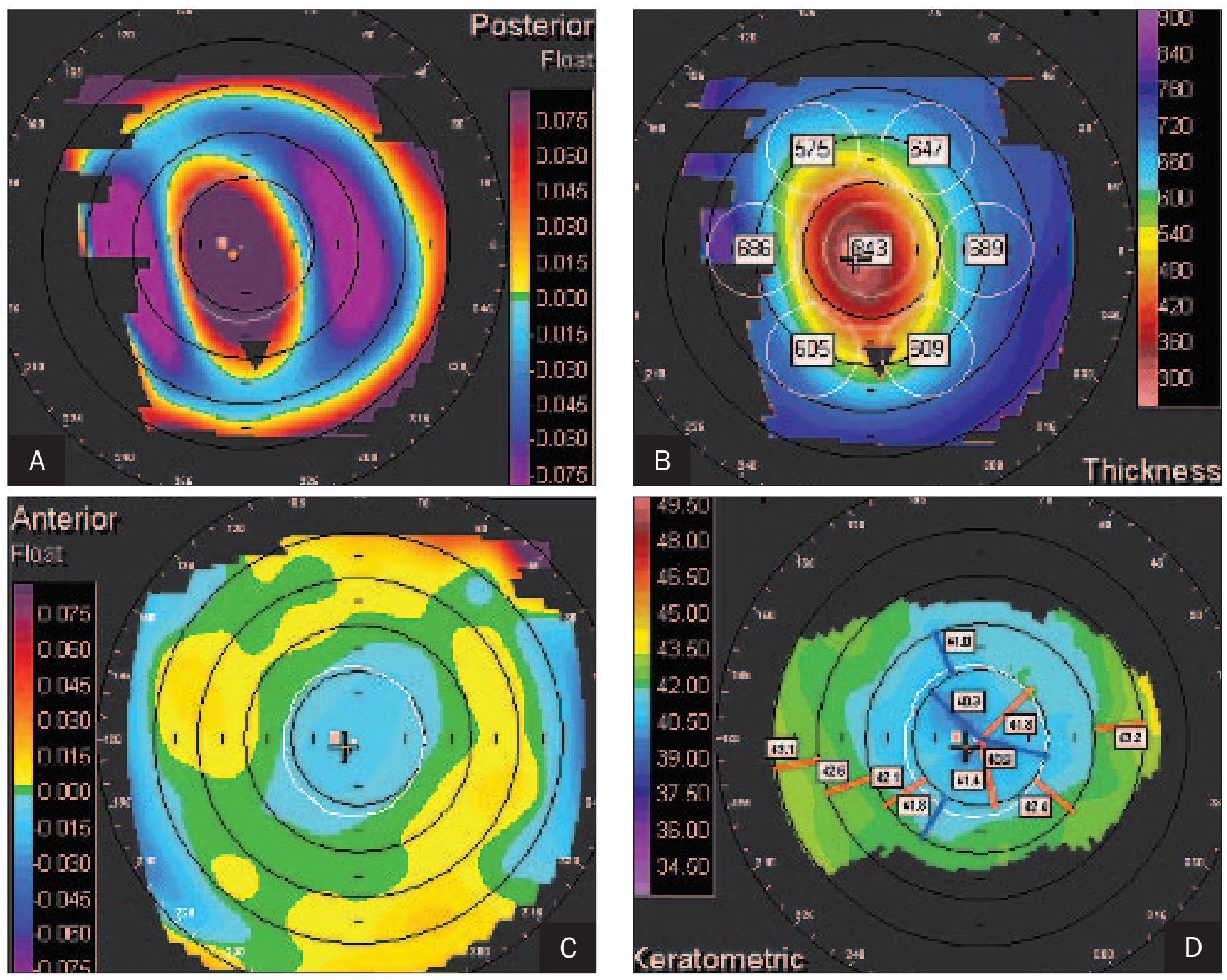

Figure 2. Orbscan topography maps of the same patient with flap edema after LASIK associated with increased IOP. A) Posterior elevation map showing a markedly high posterior float reading at the center of the cornea of $0.154 \mathrm{~mm}$, B) corneal thickness map demonstrating central thickness of $343 \mu \mathrm{m}$, C) anterior elevation map, and D) keratometric map showing a normal pattern of central flattening after myopic ablation. 

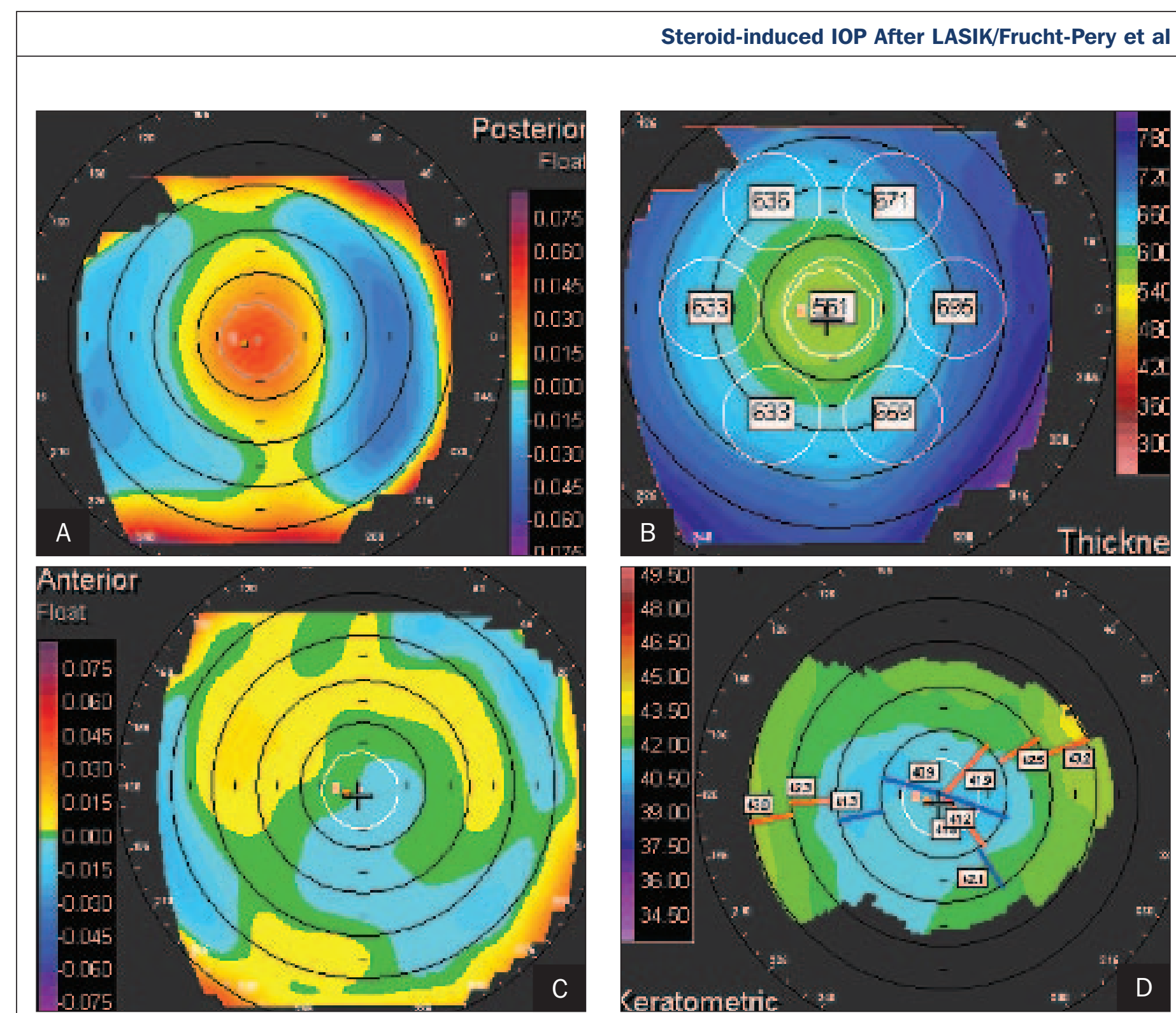

Figure 3. Orbscan topography map of the same patient in Figure 3 taken 12 hours after starting anti-glaucoma treatment. A) Posterior elevation map showing a marked decrease of the posterior float reading to $0.042 \mathrm{~mm}$ at the center of the cornea (compared with Figure $2 \mathrm{~A}$ ), B) corneal thickness map demonstrating an increase of the central thickness to $561 \mu \mathrm{m}$ (compared with Figure 2B), C) anterior elevation map, and D) keratometric map. No significant changes were noted in the anterior elevation and keratometric maps after treatment.

At final examination at 1 month, IOP was within the preoperative level or lower in all eyes. Uncorrected visual acuity improved by 1 line in 9 eyes, by 2 lines in 6 eyes, by 3 lines in 7 eyes, and by 4,5 , and 6 lines in 2 eyes each, respectively. In 1 eye, there was no change of UCVA. Two eyes lost 1 line of BSCVA, and 4 eyes gained 1 line. In 25 eyes, the final spherical equivalent refraction was within $\pm 0.50 \mathrm{D}$.

A highly significant correlation was found between the change in IOP and changes in spherical equivalent refraction and BSCVA (Fig 4). Linear regression analysis between the "net change in IOP" (IOP during the postoperative ocular hypertension - IOP at the final visit) and the "net change in spherical equivalent refraction" (spherical equivalent refraction during the hypertensive episode - spherical equivalent refraction after the drop of IOP at the last visit) revealed a highly significant correlation $\left(\mathrm{r}^{2}=0.493, P<.0001\right)$. In addition, a significant correlation was demonstrated between the net change in IOP and the "net change in BSCVA" (BSCVA during the hypertensive episode BSCVA at the last visit) $\left(\mathrm{r}^{2}=0.318, P=.0015\right)$.

\section{DISCUSSION}

Elevation of IOP after LASIK has been described previously. ${ }^{1,7,8}$ Flap edema and accumulation of fluid in the interface, between the flap and the cornea, caused a decrease in vision and erroneously low measurements of IOP by applanation tonometry. ${ }^{1-4}$ However, these events of extreme increase in IOP after LASIK with 


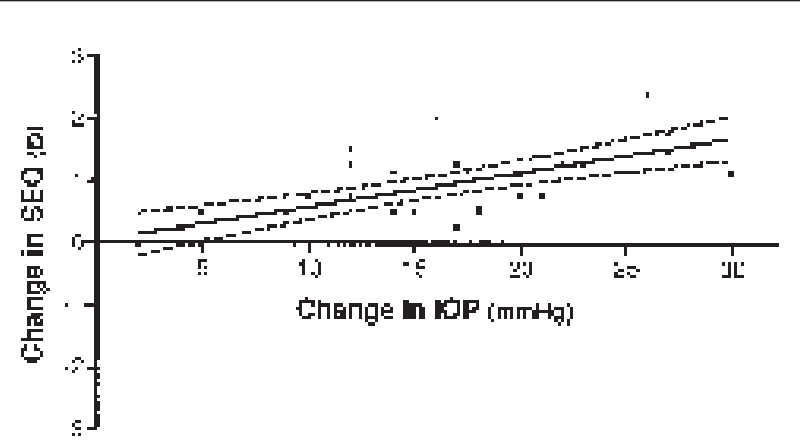

-

-

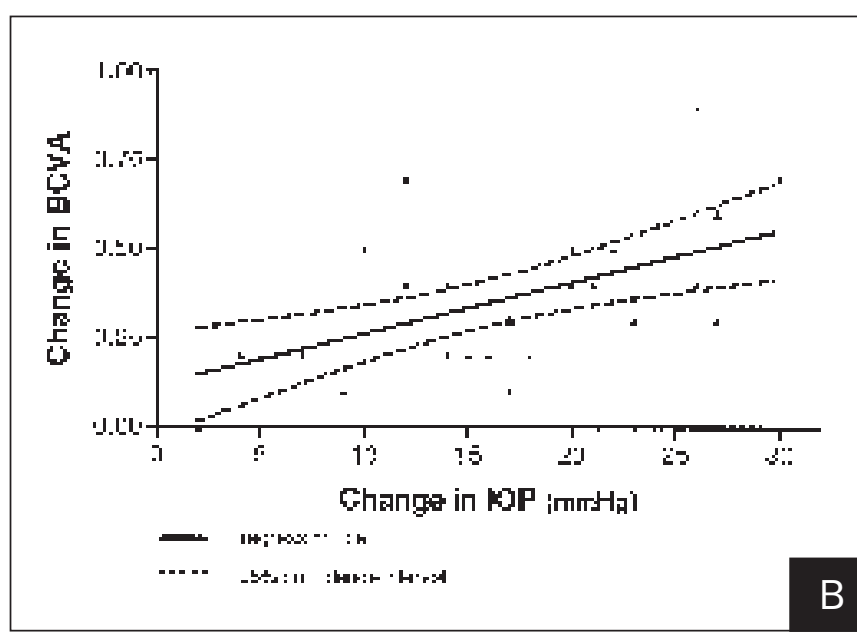

Figure 4. A) Linear regression analysis demonstrating the correlation between the net changes in spherical equivalent refraction (SEQ) and the net changes in IOP. Changes in SEQ were myopic. Changes are from the postoperative period when LASIK associated increased IOP was diagnosed through final follow-up when IOP returned to preoperative levels. A significant positive correlation was demonstrated between the net decrease in IOP to the preoperative values and the net changes in the SEQ $\left(r^{2}=0.493, P<.0001\right)$. B) A significant positive correlation was also demonstrated between the net changes in IOP and net changes in the best spectacle-corrected visual acuity for the same period between diagnosis of increased IOP after LASIK and the resolution of signs at last follow-up $\left(r^{2}=0.318, P=.0015\right)$.

fluid accumulation and concomitant measurement of low pressures are rare and were always associated with diffuse lamellar keratitis (DLK), long-term use of steroids, and occasionally with a visual field loss. ${ }^{1,3,4}$ The etiology of these events usually was attributed to endothelial dysfunction, ${ }^{9,10}$ although treatment with topical steroids could have a been a contributing factor. In previous reports of flap edema after LASIK, preexisting primary dysfunction of the corneal endothelium was considered the probable etiology. ${ }^{9,10}$ However, we believe that in our series, abrupt elevation of the IOP, caused by topical steroid use, caused a transient secondary endothelial failure, leading to flap edema.

Fifteen (1\%) of the 1492 patients who underwent LASIK reported a significant decrease in UCVA and had IOP elevations in the first 4 to 20 days postoperatively. All eyes except 1 had a decrease in visual acuity (BSCVA or UCVA), but only 3 patients complained of ocular discomfort.

Applanation tonometry revealed elevated IOP in all 29 eyes. In 14 eyes, IOP was $\geqslant 30 \mathrm{mmHg}$. The rise of IOP was accompanied by a myopic shift, decrease in UCVA, and loss of BSCVA. Interestingly, significant correlations were noted between the myopic spherical equivalent refraction change and IOP shift $(P<.0001)$ and between the BSCVA change and IOP shift $(P=.0015)$, which might suggest a direct effect of pressure variations on early residual myopia after LASIK. We did not find signs of intraocular inflammation, and the optic nerves were normal in all eyes. The decrease in UCVA and loss of BSCVA are most probably related to the flap edema, and the myopic shift. Administra- tion of anti-glaucoma treatment caused a rapid drop of IOP and partial recovery of UCVA after 1 or 2 hours. In some patients, a complete recovery of UCVA and BSC$\mathrm{VA}$ and changes in the corneal topography (posterior float) occurred within the first 24 hours after treatment. At the final examination, the pressure in all eyes was normal and no eye lost 2 lines of BSCVA.

Analysis of the Orbscan images performed in two patients may help understand the pathophysiology of the changes in visual acuity and refraction. A marked increase of the posterior float was evident postoperatively $(0.154 \mathrm{~mm})$ (see Fig 2A) and this dramatically decreased to $0.042 \mathrm{~mm}$ after reduction of the IOP (see Fig 3A). The increase of the posterior float is probably a result of a transient forward movement of the central cornea as a result of the acute increase of IOP. Although these changes could have been a result of an artifact, caused by different indices of refraction in an edematous cornea, it should be noted that almost no changes were evident on the anterior elevation and keratometric maps. Unfortunately, we were not aware of the IOPrelated posterior float changes and performed these examinations only in the last two patients of this group. The significant topographic changes and myopic shift that fluctuate in association with IOP variations may indicate the mechanical vulnerability of the cornea to IOP changes in the early postoperative period.

The myopic shift can be explained by one of two possible mechanisms. It may result from the flap edema that causes a transient change in the index of refraction, or the sudden IOP elevation may induce a transient increase of the axial length. Taken together, 
our hypothesis for the IOP elevation and myopic shift after LASIK is as follows: topical steroids after LASIK cause IOP elevation, which results in corneal endothelial dysfunction leading to flap edema. The increased IOP coupled with a reduced corneal biomechanical strength is responsible for an increase in the axial length. A possible change in the index of refraction of the edematous flap may further contribute to this myopic shift.

Our patients differ from the reported groups in the literature in that they had elevation of IOP that was not associated with DLK. ${ }^{1,3,4}$ In the published reports, inflammation in the interface and intensive use of topical steroids caused steroid-induced glaucoma, severe loss of visual acuity, stromal and flap edema, accumulation of fluid in the interface, erroneously low tonometry measurements, and late diagnosis of glaucoma. ${ }^{1,3,4} \mathrm{In}$ our patients, however, we did not find corneal inflammation or fluid accumulation (although microscopic fluid accumulation would be missed as we did not use confocal microscopy). Our patients had high IOP with applanation tonometry, mild decrease of UCVA, and were diagnosed and treated within days of the procedure. Although the actual applanation pressures might be higher by 2 to $5 \mathrm{mmHg}$ compared to our report, ${ }^{11-13}$ early diagnosis of steroid-induced IOP elevation in our patients led to discontinuation of the steroids, application of anti-glaucoma medications, and recovery of normal visual acuity and IOP within hours. The late diagnosis of steroid-induced IOP elevation after LASIK in some patients with DLK was most probably related to unfamiliarity of surgeons with such a combination of events, particularly when the measured pressures were low. Perhaps the interlamellar inflammation in the previously reported studies ${ }^{1,3,4}$ caused endothelial cell dysfunction, increase of corneal edema, and fluid accumulation in the interface cornea. These events caused prolonged and increased use of topical steroids, a further rise of IOP, and delay in diagnosis of steroid-induced glaucoma.

Decreased visual acuity in the first 2 postoperative weeks requires immediate attention. Although in high myopes an early drop in visual acuity, in an otherwise non-inflamed, asymptomatic eye, may indicate early regression of myopia; in low myopes, early significant regression of myopia with a dramatic decrease in vision is uncommon. In patients with low myopia who use steroids, who are glaucoma suspects, or have a family history of glaucoma, a complaint of decreased visual acuity after LASIK should be treated as an emergency to rule out steroid-induced glaucoma. A typical mild flap edema accompanied by residual myopia and loss of UCVA and BSCVA in an otherwise non- inflamed eye may suggest increased IOP. High IOP by applanation tonometry may indicate that the IOP is even higher. ${ }^{11-13}$ Rapid decrease of IOP and a recovery of the UCVA and BSCVA, following administration of anti-glaucoma medication, confirm the diagnosis of steroid-induced IOP elevation.

Although steroid-induced elevation of the IOP usually starts a few weeks after the initiation of topical steroid therapy, it may manifest within 3 to 5 days in extreme cases of high responders treated with frequent doses of topical steroids, such as hourly application of $1 \%$ prednisolone acetate. ${ }^{14}$ It is possible that the penetration of the steroid after LASIK surgery is more efficient as a result of the residual erosions in the conjunctiva and cornea. Other factors such as corneal shape alteration and reduced tear production may decrease the rate of the drug elimination from the ocular surface and increase the time of the drug contact with the tissue. Both mechanisms will increase the dose of the drug penetration into the eye.

We suggest decreasing the use of topical steroids after LASIK surgery. Careful and close postoperative follow-up are required in patients with a family history of glaucoma or in glaucoma suspects. ${ }^{15}$ In particular, in patients with low myopia, an early postoperative decrease in vision requires an emergency eye examination to exclude steroid-induced IOP increase. Further studies are needed to confirm our findings.

\section{REFERENCES}

1. Hamilton DR, Manche EE, Rich LF, Maloney RK. Steroid-induced glaucoma after laser in situ keratomileusis associated with interface fluid. Ophthalmology. 2002;109:659-665.

2. Rehany U, Bersudsky V, Rumelt S. Paradoxical hypotony after laser in situ keratomileusis. J Cataract Refract Surg. 2000;26:1823-1826.

3. Portellinha W, Kuchenbuk M, Nakano K, Oliveira M. Interface fluid and diffuse corneal edema after laser in situ keratomileusis. J Refract Surg. 2001;17S:192-195.

4. Belin MW, Hannush SB, Yau CW, Schultze RL. Elevated intraocular pressure-induced interlamellar stromal keratitis. Ophthalmology. 2002;109:1929-1933.

5 . Becker B. Intraocular pressure response to topical steroids. Invest Ophthalmol. 1965;4:198-205.

6. Armaly MF. Effect of corticosteroids on intraocular pressure and fluid dynamics, I: the effect of dexamethasone in the normal eye. Arch Ophthalmol. 1963;70:482-491.

7. Armaly MF. Effect of corticosteroids on intraocular pressure and fluid dynamics, II: the effect of dexamethasone in the glaucomatous eye. Arch Ophthalmol. 1963;70:492-499.

8. Nordlund ML, Grimm S, Lane S, Holland EJ. Pressure-induced interface keratitis: a late complication following LASIK. Cornea. 2004;23:225-234.

9. Loh RS, Hardten DR. Noninflammatory flap edema after laser in situ keratomileusis associated with asymmetrical preoperative corneal pachymetry. J Cataract Refract Surg. 2005;31:922-929. 


\section{Steroid-induced IOP After LASIK/Frucht-Pery et al}

10. Vroman DT, Solomon KD, Holzer MP, Peng Q, Apple DJ, Bowie EM. Endothelial decompensation after laser in situ keratomileusis. J Cataract Refract Surg. 2002;28:2045-2049.

11. Zadok D, Tran DB, Twa M, Carpenter M, Schanzlin DJ. Pneumotonometry versus Goldmann tonometry after laser in situ keratomileusis for myopia. J Cataract Refract Surg. 1999;25:1344-1348.

12. Emara B, Probst LE, Tingey DP, Kennedy DW, Willms LJ, Machat J. Correlation of intraocular pressure and corneal thickness in normal myopic eyes and after laser in situ keratomileusis. J Cataract Refract Surg. 1998;24:1320-1325.
13. Zadok D, Raifkup F, Landau D, Frucht-Pery J. Intraocular pressure after LASIK for hyperopia. Ophthalmology. 2002;109:16591661.

14. Johnson DH. Corticosteroid glaucoma. In: Epstein DL, Allingham RR, Schuman JS, eds. Chandler and Grant's Glaucoma. 4th ed. Baltimore, Md: Williams \& Wilkins; 1997:404-406.

15. Lewis RA. Refractive surgery and the glaucoma patient. Customized corneas under pressure. Ophthalmology. 2000;107:1621-1622. 